\title{
DESVIOS DA PEÇA- CONFERÊNCIA COMO SE TORNAR ESTÚPIDO EM 60 MINUTOS
}

DEVIATIONS FROM THE CONFERENCE PLAY COMO SE TORNAR ESTÚPIDO EM 60 MINUTOS

DESVIACIONES DE LA CONFERENCIA-PIEZA COMO SE TORNAR ESTÚPIDO EM 60 MINUTOS

JOÃO SANCHES ${ }^{1}$ 


\section{RESUMO}

O artigo discute estratégias de criação da peça-conferência Como se tornar estúpido em 60 minutos, encenada em Salvador nos anos de 2018 e 2019. São abordados aspectos recorrentes no teatro contemporâneo como a enunciação direta para a plateia, o discurso monodramático e as tentativas de emersão do real em cena. A perspectiva teórica do trabalho baseia-se em noções ampliadas de dramaturgia, como a proposta pelo teórico José Sanchez, assim como nas noções de crise do drama e desvio, formuladas respectivamente por Peter Szondi e por Jean-Pierre Sarrazac. O estudo ainda dialoga com o trabalho de outros artistas e teóricos como Fernando Kinas, Patrice Pavis e Erika Fischer-Lichte.

\begin{abstract}
The article discusses strategies for creating the conference play Como se tornar estúpido em 60 minutos, staged in Salvador in the years 2018 and 2019. Recurring aspects in contemporary theater are addressed, such as direct enunciation to the audience, monodramatic discourse and attempts to emerge the real on the scene. The theoretical perspective of the work is based on expanded notions of dramaturgy, as proposed by the theoretician José Sanchez, as well as on the notions of crisis of drama and deviation, formulated respectively by Peter Szondi and Jean-Pierre Sarrazac. The study also dialogues with the work of other artists and theorists such as Fernando Kinas, Patrice Pavis and Erika Fischer-Lichte.
\end{abstract}

\section{RESUMEN}

El artículo discute estrategias de la concepción de la montaje teatral Como se tornar estúpido em 60 minutos escenificada en Salvador en los años de 2018 y 2019. La pieza utiliza características recurrentes en el teatro contemporáneo, como la enunciación directa para la audiencia, el discurso monodramático y los intentos de emersión de lo real en la escena. La perspectiva teórica del trabajo está basada en nociones ampliadas de dramaturgia, segun la propuesta por el teórico José Sanchez y también en las nociones de crise del drama y desvio, formuladas respectivamente por Peter Szondi y Jean-Pierre Sarrazac. El estudio aún dialoga con el trabajo de otros artistas y teóricos, como Fernando Kinas, Patrice Pavis y Erika Fischer-Lichte.

\section{Palavras-chave:} peça-conferência; teatro contemporâneo; dramaturgia; encenação; desvio.

\section{KEYWORDS:} conference play; contemporary theatre; dramaturgy; staging; deviation.

\section{Palabras clave:} conferencia-pieza; teatro contemporáneo; dramaturgia; puesta en escena; desviación. 


\section{INTRODUÇÃO}

A CONFERÊNCIA como estratégia dramatúrgica de desvio (SANCHES, 2020) tem sido cada vez mais recorrente na cena contemporânea e sua abordagem teórica, entre outros caminhos, tem frequentemente se dado a partir da noção de "peça-conferência" (KINAS, 2005), ou “conferência-espetáculo". (PAVIS, 2017, p. 64) Uma reportagem da jornalista Maria Luísa Barsanelli, publicada em 2018 no jornal Folha de São Paulo, também reconhece essa tendência no Brasil, citando como exemplos alguns espetáculos produzidos na região sudeste: Mortos-Vivos - Uma Ex-Conferência, da companhia Foguetes Maravilha; Colônia, monólogo de Renato Livera com direção de Vinicius Arneiro; CérebroCoração de Mariana Lima; e Hamlet-Processo de Revelação, monólogo do coletivo Irmãos Guimarães com o ator Emanuel Aragão. A manchete da matéria anuncia: "Peças usam tom de palestra na disputa pela atenção do público. Espetáculos sem grandes aparatos e feitos em tom de conversa tentam cativar audiência”. (BARSANELLI, 2018)

Barsanelli (2018) destaca três aspectos comuns a essas criações cênicas: o despojamento material das encenações, as propostas de atravessamentos do real e a enunciação direta para a plateia. Este último aspecto está relacionado sobretudo ao fato de que, nas peças-conferência, ao invés de falarem entre si, as personagens, os atores e/ou performers falam majoritariamente para/com o público, 
utilizando diversas estratégias discursivas que podem misturar gêneros semelhantes como palestra, bate-papo, depoimento, confissão e relato de experiência. A jornalista considera que essas formas recentes, que se baseiam num diálogo direto com a plateia, em vez de explorar a interação, curiosamente, parecem “[...] deixar o público à vontade, imerso na encenação" (BARSANELLI, 2018, p. 1), evitando assim explorar a interatividade e investindo na proximidade, ou melhor, na empatia e na intensidade que a condição de proximidade e despojamento pode propiciar.

Em linhas gerais, baseando-nos em escritos de Fernando Kinas (2005) e Patrice Pavis (2017), entre outros, nosso trabalho compartilha a compreensão de que a “peça-conferência” corresponderia a um desejo contemporâneo de potencializar a dimensão política da cena, ou, como afirma Kinas, à tentativa “[...] de pensar em cena, pensar poética e politicamente, assumindo sem tergiversação a convergência entre ética e estética". (KINAS, 2005, p. 212) A principal característica dessas formas estaria em seu aspecto monodramático, ou seja, no fato de que elas encenam, sobretudo, o próprio pensamento. Se, numa perspectiva dramatúrgica tradicional, a cena estaria a serviço da representação de uma intriga dramática, por meio da qual se abordariam determinadas ideias, em vez disso, as peças-conferências optam por colocar as ideias em cena diretamente, explicitamente, através do corpo e das situações de enunciação que suas poéticas propõem.

Patrice Pavis (2017, p. 64-65), no Dicionário da performance e do teatro contemporâneo, destaca a dimensão política desses desvios, ${ }^{2}$ a partir dos atravessamentos entre arte e pedagogia que essas formas assumem: "Percebe-se aí sempre uma crítica da instituição artística e escolar, uma vontade de não ser somente um artista, mas um ativista, um militante político, um espectador engajado". Nesse sentido, as peças-conferência tenderiam a valorizar o caráter de assembleia do ato teatral, sua natureza “agorística”, explorando a potência do encontro presencial para o debate coletivo e, consequentemente, para a vocação política.

Por outro lado, em relação ao endereçamento direto da enunciação para o público, é importante questionar: em que medida essa estratégia pode ser um desvio com intenções estético-políticas e, ao mesmo tempo, proporcionar pouca interação, sugerindo uma espécie de situação de escuta na qual o público seria deixado “[...] à vontade, imerso na encenação". (BARSANELLI, 2018)
2 A noção de desvio, elaborada por Jean-Pierre Sarrazac $(2002,2012)$, foi desenvolvida na tese Dramaturgias de desvio (SANCHES, 2016) por meio de uma cartografia das dramaturgias encenadas no Brasil no início do século XXI. Atualmente, como desdobramento da referida tese, o presente estudo procura ampliar a abordagem com reflexões sobre a mediação de todos os elementos produtores de sentido na cena, adotando noções ampliadas e atuais de dramaturgia, como a de dramaturgia em campo expandido. (SANCHEZ, 2010) Nessa perspectiva, o desvio é uma noção operativa que indica diferenças em relação a expectativas majoritárias de recepção, ou aos modelos poéticos tradicionais. Os desvios compõem um repertório de estratégias criativas caracterizadas por autorreflexividade, mudanças de perspectiva, recursos de distanciamento. No entanto, o desvio amplia a noção brechtiana de distanciamento, pois inclui procedimentos para além dos recursos épicos, abrangendo emersões líricas e rapsódicas (SARRAZAC, 2002, 2012, 2013), entre outras recorrências contemporâneas. 0 presente estudo opera com a noção no intuito de reconhecer e refletir sobre o emergente na cena contemporânea sem adotar uma abordagem teleológica. 
Para tratar desse ponto, cabe trazer ao debate a formulação de Sarrazac (2012, p. 69) sobre um “outro diálogo” presente nas dramaturgias modernas e contemporâneas. Segundo o autor, nessas dramaturgias, seriam recorrentes personagens em estado de isolamento, com seus universos internos prevalecendo sobre as relações interpessoais. Essas construções estariam, com esses desvios, contrariando a concepção dramática hegeliana, ou de drama "absoluto" szondiana (SZONDI, 2011), que considera o diálogo entre personagens o recurso prioritário para imprimir movimento à ação. Sarrazac menciona as dramaturgias do fim do século XIX, particularmente as de Ibsen, Strindberg e Tchekhov, como antecipadoras do surgimento de peças como as de Beckett, nas quais o diálogo é ofuscado pelo monólogo, e que proliferaram a partir da segunda metade do século XX. No entanto, esses “monólogos" atuais constituiriam um tipo diferente do clássico, pois serviriam mais para suspender o diálogo tradicional do que colaborar para a progressão da ação dramática. O fato é que, nas dramaturgias modernas e contemporâneas, a relação entre as personagens tenderia a se tornar mais instável do que a de cada personagem com o leitor/espectador. Mais do que responderem umas às outras, as personagens dirigem-se com frequência para a recepção - a priori inexistente na tradição dramática rigorosa -, colocando principalmente o leitor/espectador em diálogo. Esse seria o “outro diálogo” a que se refere Sarrazac, uma interlocução cada vez mais direta entre o "dramaturgo" e o leitor/espectador (entre as instâncias produtoras do discurso e a sua recepção) - uma estratégia recorrente na cena contemporânea que fica ainda mais explícita nas referidas peças-conferência.

No entanto, é interessante observar que, paradoxalmente, “[...] é a separação, o isolamento de cada locutor que irá servir de base para a edificação desse novo tipo de diálogo. A insularidade das personagens abre espaço para uma verdadeira polifonia". (SARRAZAC, 2017, p. 201) Isso ocorre, entre outros motivos, porque, se comparados às concepções tradicionais de drama, esses desvios constituem estratégias de distanciamento que rompem com a troca interpessoal no presente das personagens. Em diversos textos modernos e contemporâneos, não apenas em peças-conferência, é evidente essa tendência de relativização dos discursos, com personagens, atores e performers direcionando a fala para a plateia, interrompendo e "denunciando" a ficção. Se os recursos do monólogo, do aparte e da narração são tão antigos quanto a arte teatral, suas aparições nas dramaturgias contemporâneas, diferentemente, têm como particularidade uma tentativa mais 
explícita de relativizar os discursos, de fugir da univocidade, de colocar diferentes

vozes e pontos de vistas em evidência e confronto. No caso específico das peças-conferências, percebe-se ainda que esses recursos convergem na tentativa de viabilizar a encenação do pensamento, a construção em cena de uma polifonia monodramática, ou “monodrama polifônico”. (DANAN, 2012, p. 113)

O presente texto procura avançar na discussão, dando continuidade ao estudo desses desvios a partir da análise de um espetáculo baiano que pode ser considerado exemplo de peça-conferência e que foi encenado por mim em Salvador, entre os anos de 2018 e 2019, período que coincide com o das peças mencionadas por Barsanelli (2018) na referida matéria. Aqui, no decorrer de nossa análise, pretendemos abordar algumas questões dramatúrgicas no sentido de refletir sobre suas articulações com o trabalho da encenação, ou de materialização da cena (dimensão performativa). Nessa perspectiva, compreendemos o termo dramaturgia para além do trabalho de composição de textos dramáticos e, de forma ampliada, a encaramos como espaço de mediação de práticas e elementos produtores de sentido na cena. Como afirma Sánchez (2011, p. 19-20, tradução nossa):

\section{É um espaço de mediação. Isso é dramaturgia: uma interrogação} sobre a relação entre o teatro (o espetáculo / o público), a atuação (que envolve o ator e o espectador como indivíduos) e o drama (isto é, a ação que constrói o discurso). Uma interrogação que é resolvida momentaneamente em uma composição efêmera, que não pode ser fixada em um texto: a dramaturgia, mais ou menos próxima do texto, sempre é resolvida no encontro instável dos elementos que compõem a experiência da cena. ${ }^{3}$

Não é possível ignorar que a data de publicação da matéria, as temporadas das montagens mencionadas por ela e a estreia do espetáculo Como se tornar estúpido em 60 minutos, do qual tratamos aqui, têm em comum o ano de 2018. Esses processos são simultâneos a uma crescente polarização política, já instalada anteriormente, mas que passou, no Brasil, por um momento determinante com as eleições presidenciais de 2018.

3 Do original: "Esto es dramaturgia: una interrogación sobre la relación entre lo teatral (el espectáculo / el público), la actuación (que implica al actor $y$ al espectador en cuanto individuos) y el drama (es decir, la acción que construye el discurso). Una interrogación que se resuelve momentáneamente en una composición efímera, que no se puede fijar en un texto: la dramaturgia está más allá o más acá del texto, se resuelve siempre en el encuentro inestable de los elementos que componen la experiencia escénica". 


\section{COMO SE TORNAR ESTÚPIDO EM 60 MINUTOS: DRAMATURGIA E ENCENAÇ $\tilde{A} O$}

Ainda em 2017, eu e o ator Rafael Medrado, com quem havia trabalhado na montagem de Egotrip (SANCHES, 2017) e que, naquele momento, estava cursando mestrado em Lisboa, decidimos trabalhar em um novo espetáculo que viria a ser desenvolvido como um diálogo entre nossas pesquisas. A primeira apresentação pública de resultado ocorreu em Lisboa, na Escola Superior de Teatro e Cinema, no âmbito de um dos componentes do mestrado que ele estava cursando. Em seguida, continuamos trabalhando até estrearmos em Salvador, em uma temporada comercial.

Incomodados com a percepção de que a radicalização política estava estimulando um recrudescimento de posições autoritárias e ultraconservadoras, de cunho fascista, que continuam ganhando adesão massiva e expressando-se sobretudo nas redes sociais (mas não apenas), decidimos que o espetáculo abordaria essas questões e deveria expressar nossa perplexidade diante de tantos retrocessos. Saímos em busca de um texto, ou discurso, que pudesse servir como ponto de partida. Em determinado momento dessa procura, lembrei do romance Como me tornei estúpido (PAGE, 2005) e entendi que aquela seria uma excelente oportunidade de colocar em prática uma vontade antiga de encenar essa obra do escritor francês Martin Page. Rafael, que ainda não conhecia o romance, depois de sua leitura, aderiu à minha proposta e, assim, demos início aos trabalhos.

O livro narra a história de Antoine, um sensível e inteligente rapaz que decide se tornar idiota para conseguir sobreviver no mundo atual e ser minimamente feliz. Escrito em terceira pessoa, com muita ironia e humor mordaz, o romance de Page (2005) apresenta diversas situações vividas pelo protagonista e mostra tanto as reflexões quanto os diálogos dele com seus amigos e com uma série de personagens com quem ele se confronta numa espécie de pequena “odisseia” contemporânea. Sofrendo por pensar demais, infeliz por sua compulsão em racionalizar e buscar compreender tudo e todos, vítima de seu excesso de empatia, a personagem tenta, de diversas formas, “se tornar estúpido" para alcançar um pouco de paz e felicidade. 
[... na expectativa de uma vida mais tranquila, Antoine tomou a

decisão de cobrir o cérebro com o manto da estupidez. Ele cons-

tatara muitas vezes que inteligência é uma palavra que designa baboseiras bem construídas e lindamente pronunciadas, e que é tão traiçoeira que freqüentemente é mais vantajoso ser uma besta que um intelectual consagrado. A inteligência torna a pessoa infeliz, solitária, pobre [...]. (PAGE, 2005, p. 7)

Eu moro em Salvador e Rafael em Lisboa, por essa razão, a maior parte do processo se deu de maneira remota, com encontros virtuais, por meio de nossos telefones celulares, através do aplicativo Facetime. Acordamos que eu ficaria responsável pela direção/encenação, incluindo nisso a concepção de cenário, figurino, iluminação e trilha, e que Rafael, além de atuar/performar e produzir, também assinaria comigo a dramaturgia, o que incluía, entre outras atividades, o trabalho sobre o romance.

Para isso, pensamos na proposta que articularia texto e encenação em uma mesma estratégia: a realização de uma conferência. Mais do que um simples desvio, a conferência foi colocada desde o início como estratégia estruturante, a partir da qual seria possível agenciar todos os elementos e dimensões do espetáculo. Decidimos transformar a história de Page, cheia de personagens secundários e narrada em terceira pessoa, em uma palestra performática onde o ator ensinaria o público a se tornar estúpido para alcançar a felicidade, a partir de sua experiência pessoal, como acontece nos famosos TEDXs. ${ }^{4}$ A personagem não seria mais Antoine e, sim, o próprio Rafael. Embora partíssemos de uma narrativa ficcional, boa parte das características atribuídas a Antoine eram consideradas muito semelhantes às nossas. Porém, o mais importante é que assumimos o discurso do romance como nosso, acrescentando informações autobiográficas, selecionando e montando os trechos do romance com os quais nos identificávamos mais e convertendo a narrativa não apenas à primeira pessoa, mas também a uma linguagem correspondente ao modo particular de falar e pensar de Rafael. Este trabalho envolveu a elaboração de uma oralidade, inscrita no texto, que extrapola a mera transposição de linguagem com o intuito de tornar a fala "natural”:
4 TED é um acrônimo de Technology, Entertainment, Design e designa um bem-sucedido projeto da fundação Sapling para disseminação mundial de ideias por meio da produção e divulgação de conferências. 
A valorização da oralidade da linguagem pode, além disso, permi-

tir ao texto dramático recuperar toda sua eficácia, mediante um trabalho sobre a respiração, ou o ritmo, reinvestindo carne nas palavras. Uma encenação que leve em conta o que a linguagem põe em jogo num texto, e o que a linguagem coloca em jogo no teatro, permite então ao espectador 'olhar-escutar um ator num duplo movimento de exibição e exposição de uma linguagem à qual o corpo se agarra' [...] Logo, essa oralidade pertence ao âmbito da teatralidade, uma vez que solicita emocionalmente - carnalmente - o espectador: ela é, em especial, operante no teatro, onde os corpos do ator e do espectador - mas da mesma forma suas subjetividades - são fisicamente convocados. (HERSANT; JOLLY, 2012, p. 129)

Fizemos nossas as palavras de Martin Page e aproveitamos essa oportunidade para ficcionalizar algumas de nossas experiências, incluindo outros conteúdos. Julgamos que, ao adotarmos o formato de conferência e o professor/palestrante como enunciador/protagonista, a dramaturgia permitiria que o discurso operasse tantos desvios (estratégias autorreflexivas) quanto fossem necessários, selecionando e desenvolvendo os tópicos que nos interessassem, de maneira ágil e dinâmica. Apesar de manter a enunciação para a plateia majoritariamente, tanto no texto quanto na encenação, também criamos cenas com diálogos no modo dramático, investindo na alternância rapsódica durante toda a montagem.

É importante destacar que a opção de encenar o livro como uma conferência se configurou como uma estratégia ao mesmo tempo dramatúrgica e de encenação. Mesmo antes de começarmos a adaptação textual, tendo como base nossas pesquisas sobre a cena contemporânea, encontramos as ideias que orientariama adaptação, a performance de Rafael e a produção de materialidades do espetáculo. O resultado foi a imediata elaboração de um projeto executivo - para captação de apoios, pautas e eventuais recursos - que apresentava uma concepção de encenação na qual estavam combinadas as múltiplas práticas cênicas produtoras de presença e visualidade, da dramaturgia à performance do ator, incluindo cenografia, figurino, iluminação e paisagem sonora. 


\section{QUESTÕ ESESPECIFICAS DEVISUALIDADE}

Baseada nas noções de rapsódia5 (SARRAZAC, 2002, 2012, 2017) e de teatro performativo ${ }^{6}$ (FÉRAL, 2015), a encenação propôs a realização de uma aula que, ao invés de utilizar projetor e slides explicativos, acompanhados de fotos ou de representações figurativas dos tópicos abordados, utilizava basicamente giz, uma mesa escolar e o próprio espaço. Optamos por uma espacialidade frontal, mais convencional, em que as paredes do teatro, sua "caixa preta", sem as vestimentas habituais (sem rotunda, pernas, bambolinas etc.), serviriam como suporte para o ator/performer desenhar e escrever palavras e imagens. Nesses espaços predominantemente pretos (chão, paredes, portas), o ator/performer desenharia com giz colorido, escreveria, anotaria citações, traduziria visualmente seus assuntos, apagando e refazendo diversas vezes, construindo a cenografia no decorrer da apresentação, ao vivo, e compondo, ao fim, uma espécie de grande mural, repleto de ideias livremente associadas, inspirado no estilo Pop Art, particularmente na visualidade das obras do artista plástico Jean-Michel Basquiat. Esse espaço preto, cheio de registros coloridos de giz, sugere uma paisagem subjetiva: a imaginativa e caótica mente da personagem - e, em última análise, de todos nós.

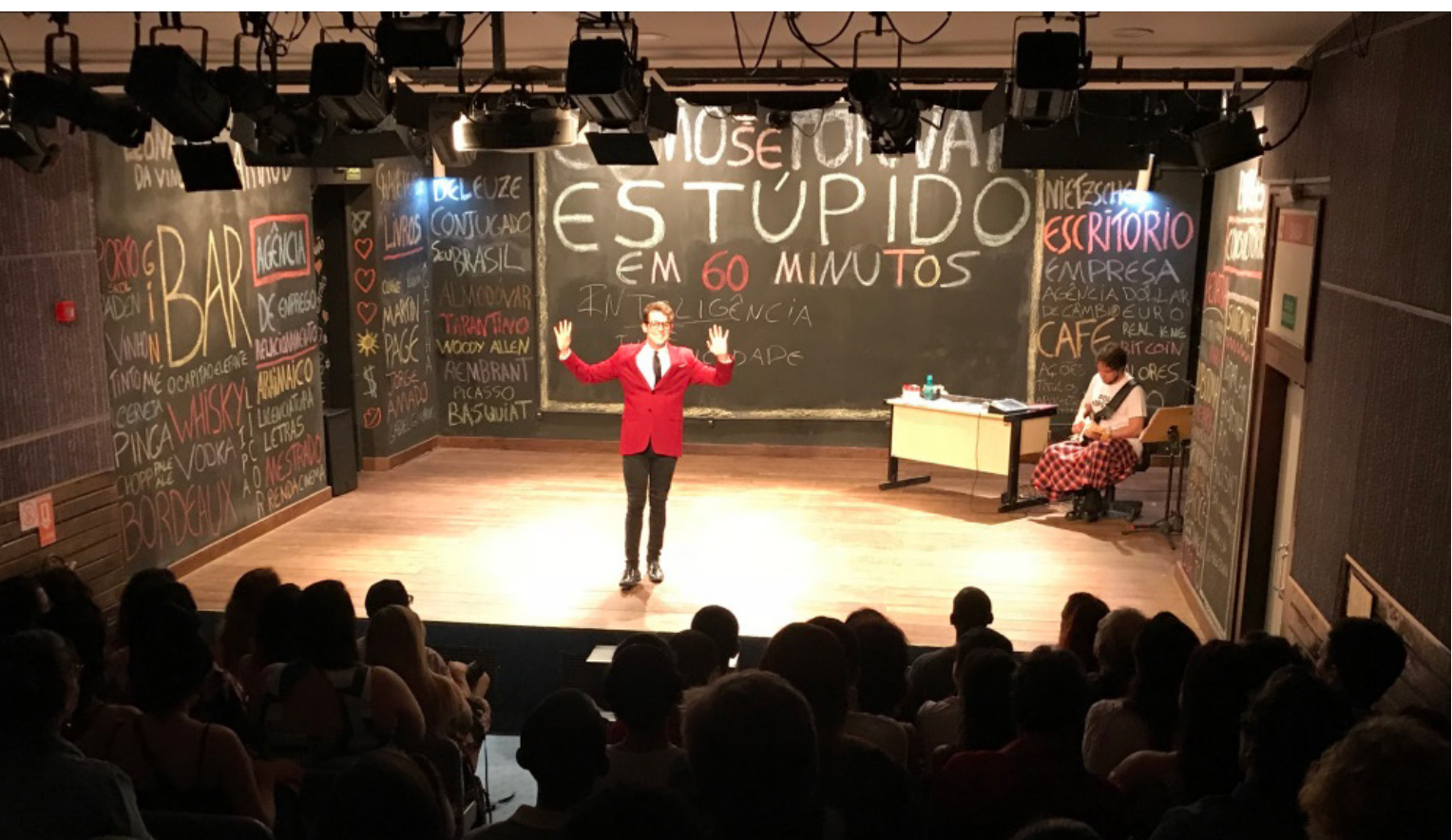

5 Rapsódia é um conceito transversal, desenvolvido por Jean-Pierre Sarrazac (2012), que indica estratégias híbridas que seriam correspondentes ao gesto do "autor-rapsodo" - criador que costura e descostura gêneros, modos e materiais diversos, numa recusa do princípio de organicidade aristotélico, conhecido como o "belo animal". São associados à rapsódia procedimentos como a montagem, a colagem, a coralidade, entre outros. (HERSANT; NAUGRETTE, 2012)

6 Teatro performativo é uma noção, desenvolvida por Josette Féral (2015), que abrange uma série de elementos recorrentes na cena contemporânea os quais, segundo a autora, estariam relacionados à influência da performance sobre o teatro. São alguns exemplos mencionados pela autora: "[...] transformação do ator em performer, descrição dos acontecimentos e da ação cênica em detrimento da representação ou jogo de ilusão, espetáculo centrado na imagem e na ação e não mais sobre o texto [...]" (FÉRAL, 2015, p. 114), entre outros aspectos atualmente discutidos na área de artes cênicas.

\footnotetext{
Figura 1: Registro fotográfico do espetáculo Fonte: arquivo pessoal do autor.
} 
Além disso, a utilização do giz, ou melhor, a recusa por novas tecnologias e a visualidade decorrente dessa escolha foram indicadas pelas características atribuídas à personagem no livro: um jovem adulto, professor universitário, intelectual, solitário, antissocial, cujo estilo pode ser associado à cultura hipster ${ }^{7}$ contemporânea. Nesse sentido, também o figurino foi pensado como uma indumentária hispter: calça black jeans slim (um pouco justa), sapatos sociais pretos, camisa social branca, acompanhados de assessórios old fashioned ("retrôs"), remetendo principalmente ao estilo dos anos sessenta e setenta, como a gravata preta slim (estreita, “fininha”); o blazer vermelho de caimento levemente acinturado; os óculos de grau com armação preta e espessa; e o tradicional relógio digital de pulso da marca Casio. Durante a aula/performance, à medida que vai discorrendo sobre os tópicos e dramatizando os acontecimentos, Rafael também vai gradativamente “desmontando" a indumentária: tira o blazer, folga a gravata, tira a camisa de dentro da calça, troca os óculos de grau por óculos de sol (também “retrôs”, estilo wayfarer) e se suja com os gizes coloridos, manchando sua roupa. No fim da aula/performance, ele se "recompõe", mas seu figurino conserva os vestígios de sua performance e transformação.

Além de construir a cenografia ao vivo por meio de interferências em giz nas paredes do espaço, o ator/performer também acionava efeitos sonoros, performando não apenas a trilha do espetáculo - ele inclusive cantava uma canção original, composta por mim para a montagem -, mas criando ao vivo paisagens sonoras que ilustravam e comentavam os acontecimentos e assuntos debatidos em cena. Posteriormente, para a temporada em Salvador, o músico Leonardo Bittencourt integrou-se à equipe e à cena, tocando guitarra ao vivo nas apresentações e executando esses efeitos sonoros, tarefa desempenhada pelo ator na primeira apresentação, experimental, em Lisboa.

Rafael Medrado também operava a iluminação, a partir da mesa de controle que ficava à vista do público, contribuindo para a criação e mudanças de atmosferas, sem ilusionismo. Seguindo uma proposta do Teatro Épico brechtiano, as luzes eram majoritariamente brancas (sem filtros de cor) e gerais (incidiam sobre todo o espaço cênico), com movimentos que tinham como principal finalidade ressaltar determinadas áreas do palco, onde o ator performaria. Os refletores estavam dispostos de maneira que, além de luzes incidindo sobre o ator, tivéssemos 
luzes direcionadas para as paredes em que ele escrevia e desenhava. Houve a utilização permanente e intensa de contraluz para conferir certa profundidade à performance, contribuindo para a percepção geral dos volumes em cena e para a valorização das materialidades. Essa dinâmica era alterada perto do fim, apenas numa determinada sequência em que a personagem narrava uma série de acontecimentos obscuros e decisivos que envolviam: um apagão elétrico em seu apartamento; uma alucinação causada pelo uso indevido de um medicamento; um sequestro relâmpago; e uma sessão inusitada de "exorcismo”, realizada por seus amigos no intuito de "trazer de volta" a sua inteligência habitual. A maior parte dessa sequência, que começa com o apagão, ocorre majoritariamente no escuro, em blackout total dos refletores do teatro. Rafael, entretanto, utiliza uma lanterna manual e cria diferentes imagens para dramatizar os acontecimentos da sequência que culmina na sessão de “exorcismo”. Na cena do “exorcismo”, os refletores do teatro voltavam a acender, porém utilizando filtros de cor correspondentes às conhecidas “luzes negras”, dando um aspecto fantasmagórico ao ator e às palavras e desenhos na parede.

\footnotetext{
Figura 2: Registro fotográfico do espetáculo Fotógrafo: Diney Araújo.
} 
Depois disso, voltava-se à luz básica do espetáculo com sua deliberada claridade, momento inclusive em que Rafael narrava a cena de seu reconhecimento: seus amigos o tinham levado para seu antigo conjugado de modo a sensibilizá-lo sobre sua conduta, pois ele havia se transformado radicalmente em seus esforços para se tornar estúpido.

Com uma estrutura material muito simples, mas de grande impacto visual e sonoro, essa sarcástica encenação convidava espectadores de todos os gêneros e faixas etárias para uma reflexão sobre os condicionamentos do logocentrismo e da cultura urbana na contemporaneidade. A primeira temporada teve um desempenho extraordinário de público: todas as sessões esgotadas por pagantes.

\section{ATRAVESSAMENTOS DO REAL EM CENA}

Por último, tratemos de um tópico que tangencia muitos aspectos das "peças-conferência”, ou "conferências-espetáculo": a questão da emersão do real em cena. Por sua abrangência, uma abordagem mais detalhada do assunto não caberia neste texto, mas é possível mencionar como o espetáculo Como se tornar estúpido em 60 minutos foi influenciado, ou procurou dialogar com essa inclinação contemporânea, já considerada uma tendência:

As nomeações diversificadas da tendência, comum no teatro contemporâneo mundial, especialmente no século XXI, funcionam como registro das árduas tentativas de apreender o leque expandido de experimentos que se liga, de um modo ou de outro, a transgressões da representação. É o período em que as artes da cena também aderem à crítica à ideologia do representado, iniciada por Marcel Duchamp com os ready-mades, e passam a incorporar realidades corporais e materiais de extrema contundência. O confronto com muitos mecanismos de simbolização e de remissão a algo que 
não está em cena enquanto materialidade e presença é feito em

proveito da presentificação única, singular, na busca de preservar a potência crítica de exposições de risco, como nota Maryvonne Saison em seu estudo sobre os 'teatros do real'. Há quase duas décadas, a ensaísta constatava a onipresença da busca pelo real na cena teatral contemporânea, que parecia indicar um desvio da mera investigação de linguagem e uma inclinação decisiva para o diálogo com a alteridade, o mundo e a história, em detrimento do fechamento da representação. (FERNANDES, 2017, p. 11)

A citação acima - que vem do texto Sintomas do real no teatro (FERNANDES, 2017), apresentação de Silvia Fernandes para o livro Autoescrituras performativas: do diário à cena, da atriz e pesquisadora Janaina Fontes Leite (2017) - sintetiza precisamente uma compreensão da qual compartilhamos. Referindo-se particularmente aos processos mencionados no livro, de cunho acentuadamente autobiográfico, Fernandes ainda considera que “[...] essas experiências talvez sejam sintomas da necessidade de encontrar algo 'verdadeiro', 'autêntico', colhido em práticas de vida e apresentado na exposição imediata do performer diante do espectador". (FERNANDES, 2017, p. 12)

Em outro texto mais extenso, Experiências do real no teatro (FERNANDES, 2013), apresentação de uma edição da revista Sala Preta dedicada ao tema e intitulada Teatros do real: memórias, autobiografias e documentos em cena, Fernandes ainda indica sinteticamente os problemas e questionamentos conceituais que a abordagem do real na cena provoca:

[...] a opção por abrir brechas no simbólico para permitir que a matéria do teatro e do contexto social, especialmente o corpo do artista e o espaço da cidade, estejam implicados no processo crítico é um modo inédito de renovar a tradição de combate e engajamento. Um dos mecanismos para isso seria a 'difração', tradução limitada para o termo usado por Saison, effraction, que ganha contundência quando associado ao rasgo e à fratura. É como se a representação da realidade fosse inoperante e devesse ceder lugar à irrupção da própria realidade em cena. 
No entanto, é importante registrar os problemas conceituais que a questão do real no teatro levanta. Para pesquisadores de inegável seriedade, como Philip Auslander, Herbert Blau, José Da Costa e Luiz Fernando Ramos, a tentativa de difração não passa de esperança ingênua de acesso direto às próprias coisas, uma espécie de sonho impossivel de dispensar a mediação dos sistemas de representação, que o simples uso da linguagem determina. O simulacro, a simulação e a palavra soprada, para emprestar conceitos de Jean Baudrillard e Jacques Derrida, são indícios inequívocos da impossibilidade de escapar do simbólico. (FERNANDES, 2013, p. 5)

Como é possível perceber, a importância dessa tendência na cena contemporânea, sua complexidade e abrangência já são amplamente reconhecidas e as peças-conferências, particularmente, constituem-se em uma das práticas cênicas desenvolvidas nessa perspectiva. Especificamente em relação a Como se tornar estúpido em 60 minutos, destacam-se três momentos do espetáculo em que procuramos abrir espaço para outras emersões do real, além das já mencionadas.

O primeiro momento é antes do início formal da conferência-espetáculo. Quando a porta do teatro era aberta e o público acessava a sala, Rafael Medrado e Leonardo Bittencourt estavam no palco e as paredes já estavam cobertas de palavras escritas à giz, com alguns espaços vazios, reservados para novas anotações. Eles cumprimentavam conhecidos e desconhecidos, conversavam com o público e entre si, numa atmosfera descontraída e espontânea. Nesse momento prévio, Rafael aproveitava para convidar pessoas na plateia para escreverem, ou desenharem na parede lateral do palco algo que elas considerassem "sintomas de estupidez". Havia uma interação do público e comentários jocosos na plateia a respeito daquilo que cada um escrevia. Antes mesmo da aula ser formalmente iniciada, o espetáculo obviamente já estava em curso e a primeira ação era atribuída ao público. Depois, no decorrer da apresentação, Rafael fazia menção àquelas palavras de maneiras diversas, não deixando essa intervenção coletiva restrita àquele momento prévio.

O segundo momento considerado por nós como uma abertura da ficção para a realidade era a cena em que o guitarrista falava. Na montagem, Rafael performava "ele próprio", na versão professor/conferencista. Na dinâmica de narrar, comentar 
e também de dramatizar algumas cenas em que havia diálogo entre diferentes personagens, ele tinha que dar conta das réplicas de todos os interlocutores. Para isso, não havia nenhum recurso teatral especial, ou convenção específica: Rafael simplesmente, como alguém que está contando para amigos uma cena que presenciou, enunciava as narrações e diálogos, de maneira espontânea e sem marcações rígidas. No palco, no entanto, havia certa espacialidade prevista: determinadas cenas e/ou tópicos da peça tendiam a ocorrer em áreas do palco nas quais já estavam nas paredes palavras e imagens associadas. Por exemplo: na parede lateral do proscênio, à esquerda do público, estava escrito "bar" e uma série de nomes de bebidas; à direita, “consultório" e nomes de remédios e sintomas, e assim por diante. Quando Rafael tinha que se referir a um tópico, ou narrar e dramatizar uma cena que supostamente ocorrera em um ambiente relacionado àquelas palavras, sua tendência era ir para a respectiva área do palco, inclusive sublinhando, riscando, apagando e escrevendo novos termos. Mas esse trânsito não era rígido, nem definitivo, durante as apresentações havia deslocamentos novos e, mesmo dentro dos previstos, criamos zonas de indefinição. Entretanto, na reta final do espetáculo, em uma sequência já mencionada neste artigo, ocorria a primeira cena que contrariava essa dinâmica:

\section{RAFAEL}

Chegando em casa, eu encontrei um pacote na porta. Era uma edição de bolso do livro Diferença e Repetição de Gilles Deleuze. Meu Deus, meu coração disparou. Eu chorei, não consegui me conter. Meu livro preferido. Com certeza esse atentado era obra dos meus antigos amigos, que queriam me recuperar. Rapidamente corri, tomei 4 comprimidos de Felizac e, com medo de me contaminar, deixei o livro na mesa e fugi pra televisão. Zapiei com o controle remoto a noite toda. Eu já tava hipnotizado quando, de repente, faltou luz. Percebi pela silhueta que tinha um homem em minha sala. Apesar da overdose de Felizac, eu me caguei de medo. RAFAEL

Quem é você?? Vocêé o Robin-Hood? Você quer me matar? Você é um serial killer? 


\section{GUITARRISTA}

Falso. Tudo em vocêé falso, Rafifa. Eu não sou Robin-Hood, nem ladrão, nem serial killer. Você acha que um serial killer ia usar saia? RAFAEL

Não sei. Você é escocês? Você parece com um amigo meu, guitarrista, você fala como ele, mesma cara estranha, o cabelo desgrenhado, umas piadas horrorosas. Seu nome é Leonardo Bittencourt?

GUITARRISTA

Você se engana, Rafifa. Eu sou o fantasma de Leonardo Blttencourt.

RAFAEL

Meu Deus, Leo morreu? [...]. (MEDRADO; SANCHES, 2018)

Como é possivel perceber, o interlocutor de Rafael na cena é o guitarrista Leonardo. A cena era performada por eles da seguinte forma: havia um black out e o diálogo citado acima começava com Rafael apontando uma lanterna acesa na direção do público - colocando-o no lugar de interlocutor -, porém, o interlocutor era o guitarrista. Quando Rafael falava, ligava a lanterna em direção ao público e só apagava quando terminava a réplica; quando era a vez de Leonardo falar, sentado no mesmo lugar onde tocava sua guitarra durante a apresentação, ele abria a capa de seu Ipad - usado por ele para a execução da trilha - e a luz da tela do tablet iluminava seu rosto. Imediatamente, no microfone, ele enunciava (ou lia no Ipad) sua réplica e, em seguida, fechava a capa, novamente voltando ao escuro. Esse diálogo entre eles ocorria com essa alternância de luz, espaço e som.

Embora se trate da dramatização, ou da recriação de uma cena ficcional, tirada do livro de Page (2005), há um deliberado jogo performativo que procura instaurar certa liminaridade na recepção, principalmente, por meio da participação de Leonardo Bittencourt. Em primeiro lugar, a cena original, de Martin Page, é um pouco diferente e ocorre entre Antoine e Danny Brillant (um cantor popular francês, real). Nossa cena manteve a mesma função narrativa da cena correspondente no romance (alertar o protagonista para o excesso de medicação e de estupidez a que estava se entregando), mas, para isso, incorporamos explicitamente dados da nossa realidade imediata, dados do contexto virtual e efetivo da performance, como a presença de 
Leonardo Bittencourt; a relação entre os dois; o perfil do Instagram de Leonardo (que ele divulgava enfaticamente); a peça do figurino (saia) que ele vestia na apresentação etc. Além disso, os efeitos visuais dessa cena eram resultado da ação ao vivo dos enunciadores/performers que manipulavam laterna e Ipad, no caso do Ipad do guitarrista, subvertendo a função atribuída ao instrumento até aquele momento da apresentação. Dois pequenos detalhes: a lanterna é utilizada por Rafael de modo a ajudá-lo visualmente a narrar a cena em que o diálogo evocado teria ocorrido; já a luz do Ipad é usada por Leonardo apenas para iluminar seu rosto enquanto ele fala, ele sequer olha para Rafael (que está no escuro), seu olhar é direcionado para a fonte de luz, a tela do Ipad, onde se encontram os textos que ele tem que enunciar. Em síntese, há diversos desvios de encenação, estratégias de distanciamento, valorização das materialidades e presenças, não se instala uma representação ilusionista, há uma performance dos dois cuja ação é narrar a cena à qual se quer fazer menção.

O terceiro momento de irrupção da realidade, ou previsto para tal, se dava na cena final e era ainda mais efetivo e arriscado. No fim do livro de Page (2005), Antoine, depois de passar por diversas situações e conseguir “se tornar estúpido", é convencido por seus antigos amigos a voltar à sua “versão original”. Há uma passagem de tempo e chega-se à cena final do romance: o encontro de Antoine com Clémence. Ele conhece a garota numa praça, de maneira inusitada. Eles travam um diálogo quase nonsense, passam por uma rápida e intensa situação de perigo, e o romance se conclui com o passeio dos dois pelas ruas, brincando de fantasma, “[...] começaram a assombrar a cidade”. (PAGE, 2005, p. 158)

Para o espetáculo, nos baseamos em parte do diálogo de Page, mas incluímos dados autobiográficos e o principal: incluímos a noiva de Rafael Medrado, Luana Bistane, e a relação entre os dois na cena. Destaque-se que Luana é produtora cultural, não é atriz, ou performer. Com o desejo e a concordância de Luana em se aventurar nessa nova experiência, combinamos que ela assistiria ao espetáculo, na plateia, como qualquer outra espectadora e, em determinado momento, se levantaria. Rafael então desceria do palco, iria até ela e os dois iriam dialogar. Abaixo, seguem trechos da cena (já adaptada em função da performance): 
RAFAEL

O tempo passou e, num domingo de manhã, eu saí do meu conjugado, caminhei até o Campo Grande, sentei num banco, olhei pra frente e vi uma mulher. Ela me olhou, me examinou como se eu fosse uma escultura da praça e, por fim, me estendeu a mão. Eu quis falar, mas ela não deixou.

(A partir desse momento, o ator contracena com a sua namorada/ noiva/esposa real, ou com a voz dela em off)

LUANA

Eu tô procurando meus amigos.

\section{RAFAEL}

Como eles são?

LUANA

Como você, talvez. De uma qualidade superior.

\section{RAFAEL}

Qualidade superior...Você parece que tá falando de um presunto. LUANA

Não, não tô falando de presunto, eu não como carne.

$[\ldots]$

\section{RAFAEL}

Luana me puxou e me levou pro meio da rua.

LUANA

Pode abrir os olhos.

RAFAEL

Meu Deus, Luana, tá vindo um carro!

$[\ldots]$

LUANA

Jure que confia e pare de gemer, seu medroso. Não se mexa, isso é muito importante. Jure.

RAFAEL

Tá bom, eu juro. Eu não vou me mexer, eu não vou... me mexer...No penúltimo instante, Luana me puxou pelo braço, nós dois caímos no meio da calçada. O carro passou raspando, buzinando e xingando. 
LUANA

Eu salvei a sua vida, Rafael. Eu sou sua heroína! Agora a gente tá ligado pro resto da vida. Daqui pra frente, a gente é responsável um pelo outro. Como os chineses.

$[\ldots]$

RAFAEL

Senhoras, senhores, hoje eu vivencio overdoses diárias de emoção. (confere o relógio) O nosso tempo já acabou e a gente precisa concluir. Bem, eu espero que as experiências relatadas aqui sejam úteis de alguma forma. Pra quem acha que eu não consegui me tornar estúpido e que voltei a ser como era no início da história, essa é a minha última e mais preciosa lição. Aqueles que não são estúpidos já devem ter percebido que eu me apaixonei perdidamente por Luana. Pois é. E continuo apaixonado. E digo mais: estamos noivos e vamos nos casar em breve. Essa é a minha lição final: se os senhores querem realmente se tornar estúpidos, arranjem um jeito de se apaixonar e, se forem correspondidos, casem! Amigos, amigas, senhoras e senhores, se apaixonem, gozem, amem, casem. Não tem estratégia melhor do que o Amor para quem quer se tornar estúpido - e feliz. Muito obrigado. (MEDRADO; SANCHES, 2018)

Procuramos não "dirigir" Luana, pedimos apenas que ela falasse um pouco mais alto do que normalmente e deixávamos a cena acontecer. O texto final citado acima, enunciado por Rafael, além de atestar e reafirmar, a cada apresentação, a relação do casal (que ainda está junto até o momento), também funcionava de maneira irônica, pois o discurso, ao mesmo tempo que preconizava a paixão, o casamento, o Amor, também os indicava como principal e mais efetivo caminho para se tornar estúpido.

É importante esclarecer que havia um segundo formato para cena, quando não era possível ter Luana presente. Ela esteve em quase todas as apresentações da primeira temporada e em algumas da segunda. Mas ela não estava ali como profissional e, sim, como companheira de Rafael, quando era possível. Por isso, algumas vezes, a cena ocorria com a mesma movimentação, porém utilizávamos 
uma gravação de sua voz, em off, com a qual Rafael contracenava. Nesses dias,

nos agradecimentos, costumávamos usar o tablet de Leonardo Bittencourt e fazer rapidamente uma vídeo-chamada com Luana (onde ela estivesse), para que o "dado de realidade" ficasse mais explícito. Ela cumprimentava o público, falava o que quisesse e se despedia de todos.

Nessa última versão, o atravessamento do “real” ficava explícito posteriormente. Mas, na primeira versão, com Luana emergindo da plateia, certa liminaridade instaurava-se com a sua presença e o público passava por uma espécie de crise na qual era preciso ajustar a percepção. “O que está ocorrendo aqui?”, "Quem é ela? Uma atriz convidada?”, “Não era um solo? A ficha técnica anunciava o nome dela no elenco?”, “O que esse diálogo dos dois significa?”, “Ela é a namorada dele realmente?" são exemplos de questionamentos que ocorriam a muitos espectadores enquanto a cena acontecia e que nos foram relatados posteriormente.

\section{CONSIDERAÇÕES FINAIS}

É possível identificar nesses relatos um fenômeno que, em certa medida, corresponderia ao jogo com a multiestabilidade perceptiva à qual se refere a teórica alemã Erika Fischer-Lichte (2013), por exemplo, no artigo Realidade e ficção no teatro contemporâneo, publicado na revista Sala Preta, na edição já referida aqui. Para a Fischer-Lichte (2013, p. 16), “Em toda interpretação, surge uma tensão particular entre o corpo fenomenal e o corpo semiótico, entre o real e o ficcional". A autora reconhece que, em qualquer espetáculo, há duas ordens perceptivas as quais ela denomina de ordem da presença e ordem da representação: 
função de personagem ficcional particular. [....] O processo de

percepção, evidentemente, tem por finalidade dar vida a uma figura dramática. Os elementos percebidos, que não podemos considerar como signos da figura, não serão levados em conta no processo em andamento da produção de sentido. [...] outra ordem, que chamarei de ordem de presença, obedece a princípios completamente diferentes. O corpo do ator é percebido em sua fenomenalidade, naquilo que constitui o seu estar-no-mundo particular. Esta acepção induz um certo número de associações, lembranças, fantasias que, na maioria dos casos, não têm relação direta com o elemento percebido. [...] A multiestabilidade perceptiva, que se manifesta no momento do deslocamento de uma ordem para outra, é responsável por aquilo que nenhuma das duas é capaz de estabilizar de maneira permanente. [...] Quando, durante um espetáculo, a percepção muda repetidamente e, devido a este fato, o espectador é frequentemente transportado a um estado entre as duas ordens, tal diferença perde cada vez mais sua pertinência e, ao contrário, a atenção do sujeito que percebe fixa-se na ruptura da estabilidade, no estado de instabilidade, na passagem. (FISCHER-LICHTE, 2013, p. 20)

Os espetáculos que a autora comenta no referido texto (FISCHER-LICHTE, 2013) são exemplos radicais de propostas performativas de irrupção do real, de desestabilização perceptiva, de criação de liminaridade. Como se tornar estúpido em 60 minutos, evidentemente, está muito longe do nível de radicalidade que pode ser reconhecido nos exemplos mencionados por ela. No entanto, em sua condição de peça-conferência/conferência-espetáculo e em muitas estratégias de desvio deliberadamente adotadas pela encenação e dramaturgia, mencionadas neste artigo, procurou-se criar as fraturas, difrações ou, em nossas palavras, as oportunidades de atravessamentos do real que julgamos necessárias para conferir potência às ideias, encaminhar o processo criativo e colocar, assim, nosso pensamento-ação em cena. 


\section{REFERÊNCIAS}

BARSANELLI, M. L. Peças usam tom de palestra na disputa pela atenção do público.

Folha de S. Paulo, São Paulo, 21 out. 2018. Disponível em: https://www1.folha.uol.com.br/ ilustrissima/2018/10/pecas-usam-tom-de-palestra-na-disputa-pela-atencao-do-publico. shtml. Acesso em: 13 abr. 2020.

DANAN, J. Monodrama (polifônico). In: SARRAZAC, J-P. (org.). Léxico do drama moderno e contemporâneo. São Paulo: Cosac Naify, 2012. p. 113-115.

FÉRAL, J. Além dos limites: teoria e prática do teatro. São Paulo: Perspectiva, 2015.

FERNANDES, S. Experiências do real no teatro. Sala Preta, São Paulo, v. 13, n. 2, p. 3-13, 2013.

FERNANDES, S. Sintomas do real no teatro. In: LEITE, J. F. Autoescrituras performativas: do diário à cena. São Paulo: Perspectiva: FAPESP, 2017. p. 11-14.

FISCHER-LICHTE, E. Realidade e ficção no teatro contemporâneo. Sala Preta, São Paulo, v. 13, n. 2, p. 14-32, 2013.

HERSANT, C.; JOLLY, G. Oralidade. In: SARRAZAC, J-P. (org.). Léxico do drama moderno e contemporâneo. São Paulo: Cosac Naify, 2012. p. 129-131.

HERSANT, C.; NAUGRETTE, C. Rapsódia. In: SARRAZAC, J-P. (org.). Léxico do drama moderno e contemporâneo. São Paulo: Cosac Naify, 2012. p. 152-155.

KINAS, F. Carta aberta: uma peça conferência, numa cidade em repouso, para um banquete público. Sala Preta, São Paulo, v. 5, p. 209-214, 2005.

LEITE, J. F. Autoescrituras performativas: do diário à cena. São Paulo: Perspectiva: FAPESP, 2017. MEDRADO, R.; SANCHES, J. Como se tornar estúpido em 60 minutos. Salvador, 2018. (Peça não publicada).

PAGE, M. Como me tornei estúpido. Rio de Janeiro: Rocco, 2005.

PAVIS, P. Dicionário da performance e do teatro contemporâneo. São Paulo: Perspectiva, 2017.

SANCHES, J. A conferência como estratégia dramatúrgica de desvio. Cena, Porto Alegre, n. 31, p. 300-311, 2020.

SANCHES, J. Dramaturgias de desvio: recorrências em textos encenados no Brasil entre 1995 e 2015. 2016. Tese (Doutorado em Artes Cênicas) - Universidade Federal da Bahia, Salvador, 2016. Disponivel em: https://repositorio.ufba.br/ri/bitstream/ri/19583/1/TESEJOÃOSANCHES.pdf. Acesso em: 14 mar. 2021.

SANCHES, J. Egotrip: ser, ou não ser? Eis a comédia. Salvador: Edufba, 2017.

SÁNCHEZ, J. A. Dramaturgia en el campo expandido. In: BELLISCO, M.; CIFUENTES, M. J.; ÉCIJA, A. (ed.). Repensar la drama- turgia. Murcia: CENDEAC, 2011. p. 19-37.

SARRAZAC, J-P. (org.). Léxico do drama moderno e contemporâneo. São Paulo: Cosac Naify, 2012. SARRAZAC, J-P. O futuro do drama: escritas dramáticas contemporâneas. Porto: Campo das Letras, 2002.

SARRAZAC, J-P. Poética do drama moderno: de Ibsen a Koltès. São Paulo: Perspectiva, 2017. 
